\title{
Application and development of ground source heat pump technology in China
}

\author{
Chaofan Song, Yang Li, Taha Rajeh, Ling Ma, Jun Zhao *iD and Wenjia Li
}

\begin{abstract}
Ground source heat pumps (GSHPs) are one of the renewable energy technologies with features of high efficiency, energy saving, economic feasibility and environmental protection. In China, GSHPs have been widely used for building heating and cooling in recent years, and have shown great potential for future energy development. This paper summarizes the classification, development history, and use status of shallow GSHPs. Several typical engineering cases of GSHP technology are also specified and analyzed. Finally, promising development trends and some advanced technologies are illustrated.
\end{abstract}

Keywords: Shallow geothermal energy, Ground source heat pump, Case analysis

\section{Introduction}

With the rapid growth of China's construction industry, energy demand and energy saving for building heating and cooling are of great importance [1]. In the year 2019, significant achievements were made in the development and use of geothermal energy in China. By the end of 2019, the construction areas with shallow geothermal energy applied had reached around 841 million square meters in China, ranking first in the world. Among the shallow geothermal energy technologies, ground source heat pumps (GSHPs) have the advantages of energy saving, high efficiency, environmental protection, and cleanliness, and consequently, they are widely used in building HVAC applications. Consuming low electric power, the technology of GSHPs can transfer low-temperature thermal energy to high-temperature thermal energy. With this technology, reservoirs in shallow ground layers, including soil formation, aquifers or lakes, etc., can be used as the heat source for heating in winter, or as the heat sink for cooling in summer. From 2020, the development and use of geothermal energy in China is showing wide application prospects, featured by the large-scale development of shallow geothermal

\footnotetext{
* Correspondence: zhaojun@tju.edu.cn

Key Laboratory of Efficient Utilization of Low and Medium Grade Energy, Ministry of Education of China, Tianjin University, Tianjin 300350, China
}

heating (cooling), the promotion of a commercial development mode of medium and deep geothermal heating, and the wide application of "geothermal energy +" [2].

\section{Shallow GSHPs}

\subsection{Classification of shallow GSHPs}

The most common usage of GSHPs is for central airconditioning systems. With the rock soil, ground soil, and groundwater or surface water used as low-temperature heat sources, GSHPs are composed of the heat pump unit on the source side, and a geothermal energy exchange system and load system on the building side. Deriving from the different forms of geothermal energy exchange systems, GSHP systems can be divided into ground-coupled heat, groundwater heat and surface water heat pump systems.

\subsubsection{Ground-coupled heat pumps}

A ground-coupled heat pump (GCHP) system uses shallow soil as heat source or heat sink. It is composed of a group of borehole heat exchangers and heat pump units buried in the ground. It is called 'closed loop', also known as closed loop GSHP or soil source heat pump. In summer, water or antifreeze solution circulates through the pipeline to release the indoor heat to the underground rock and soil layer, whereas in winter, the 

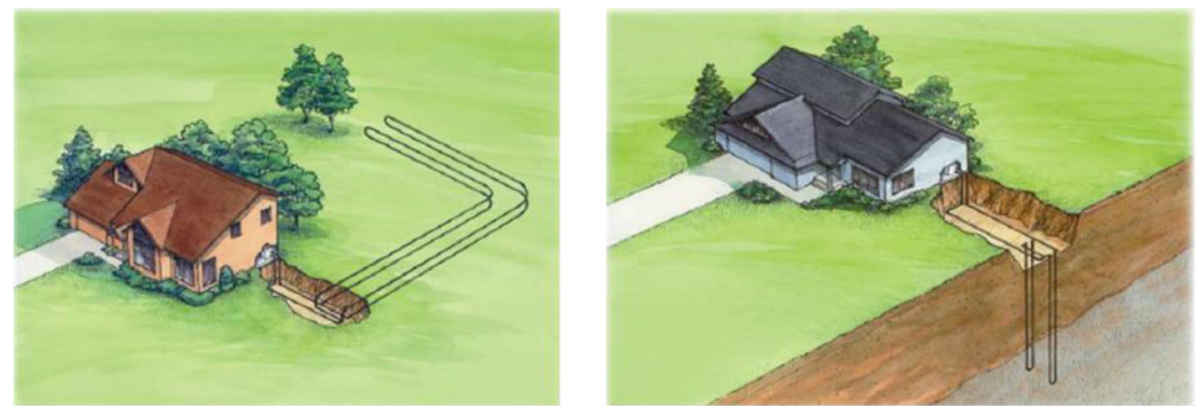

Fig. 1 Ground-coupled heat pumps. a Horizontal buried pipe systems; b vertical buried pipe systems

circulating medium extracts the heat from the underground rock and soil layer to heat the buildings.

According to the different running directions of refrigerants, loops form refrigeration and heating cycles. From the different pipe layouts of the ground source heat exchangers, the ground-coupled heat pump system can be further divided into the horizontal and the vertical, as schematically shown in Fig. 1.

\subsubsection{Groundwater heat pumps}

The groundwater source heat pump system uses low-grade groundwater as the heat source, and its schematic diagram is shown in Fig. 2. In winter, the heat pump unit absorbs heat from the groundwater provided by the water intake well. After improving the grade, the heat pump unit supplies heat to consumers such as buildings. After releasing the heat, the groundwater is recharged back to the ground through the return well, and some of the cold energy can be stored at the same time. In summer, the water intake well and return well will be exchanged (a submersible pump should be installed in both the intake well and backwater well). It is conducive to the maintenance of the wells while making full use of the cold storage in winter.

\subsubsection{Surface water heat pumps}

Surface water refers to all kinds of water bodies stored on the land surface. Rivers, lakes, reservoirs, artificial lakes, seas, and urban sewage are all suitable for the cold and heat sources of surface water ground-source heat pump systems.

Surface water heat pump systems are divided into open and closed systems. The open system is similar to the groundwater source heat pump system. Water is pumped from the water body, and then it is sent to the heat pump unit or plate heat exchanger, and discharged back to the original water body after heat exchange. The closed system is similar to the ground-coupled heat pump system. The heat exchange coil is placed at the bottom of a water body at a certain depth as schematically shown in Fig. 3, and the circulating medium in the coil exchanges heat with the water body.

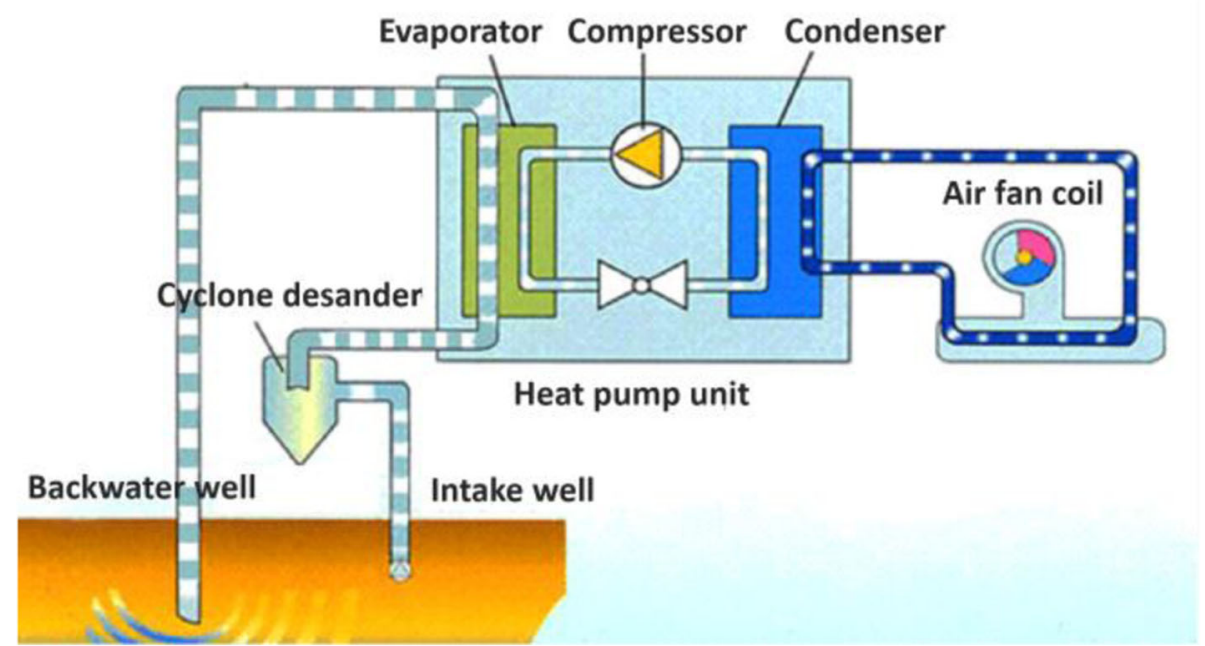

Fig. 2 Groundwater heat pumps 

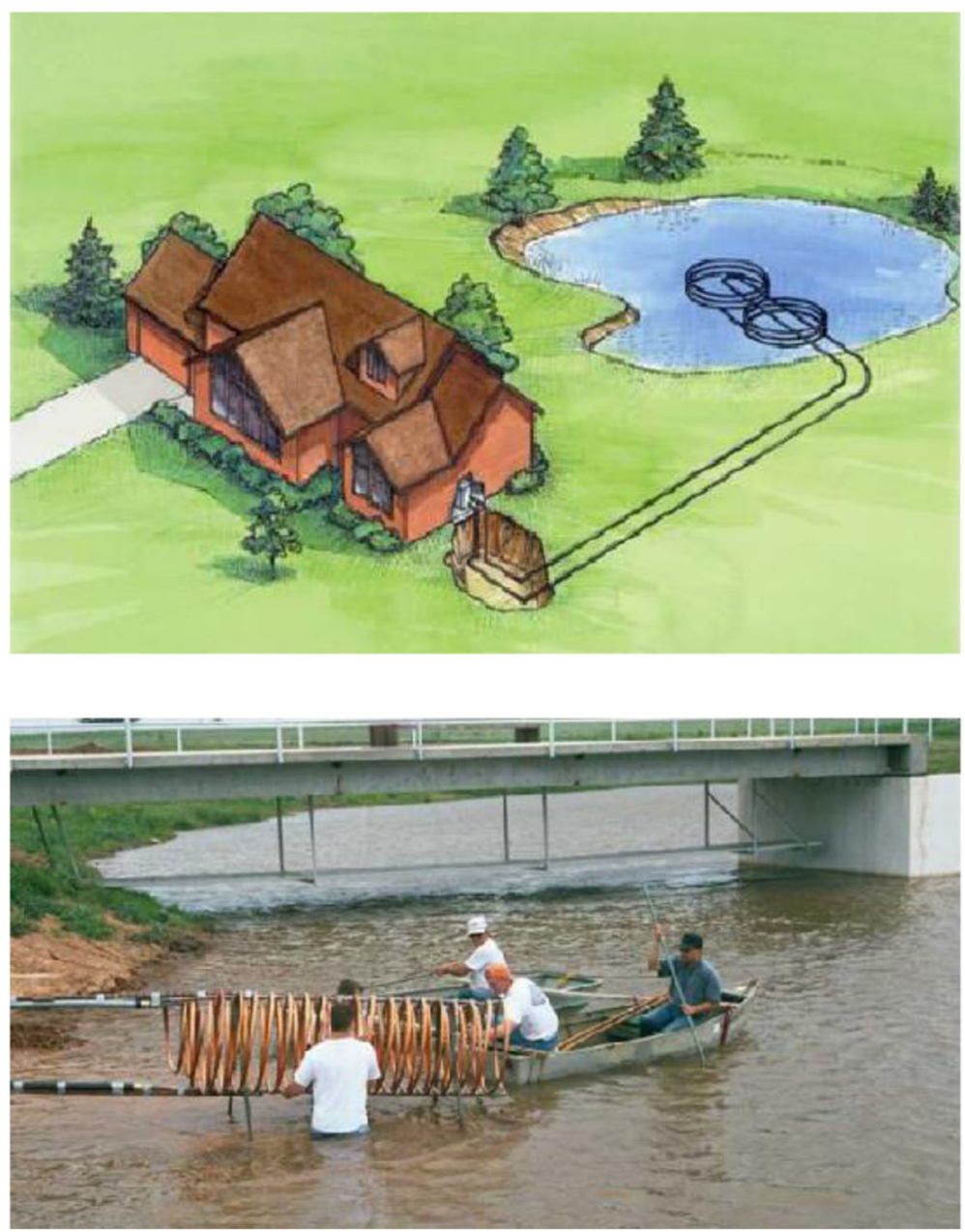

Fig. 3 Surface water GSHPS

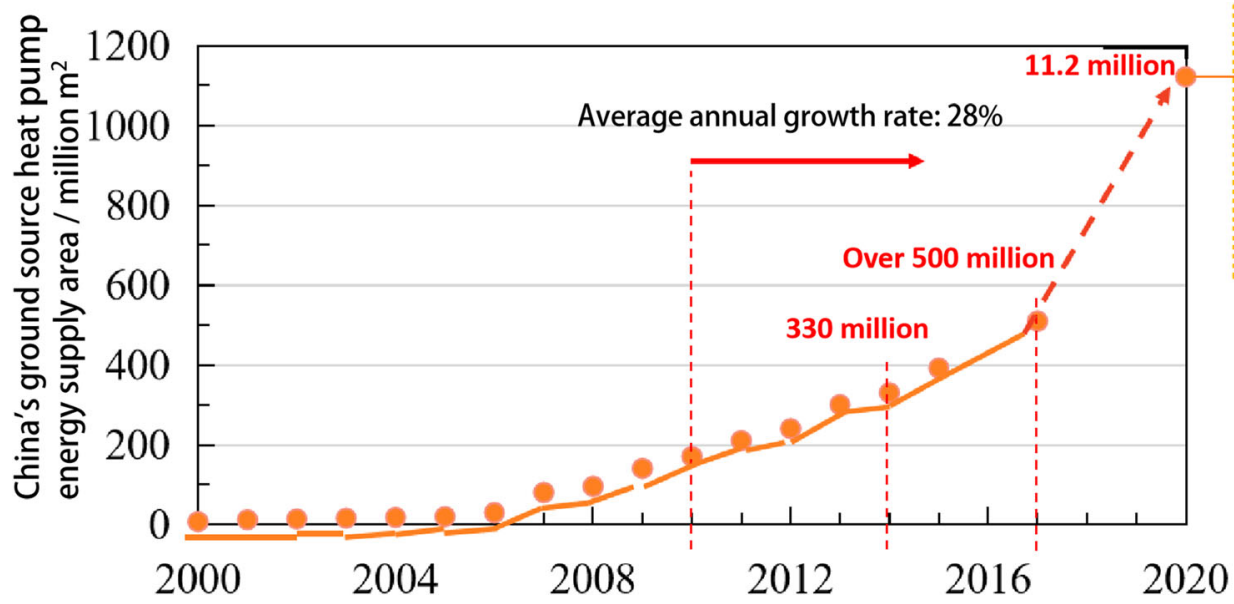

In the 13th Five-Year Plan for geothermal energy, an area of 700 million square meters of shallow geothermal energy will be added, which is 1.85 times higher than that in the 12th Five-Year Plan.

Fig. 4 Annual variation of energy supply area of GSHPs in China [4] 

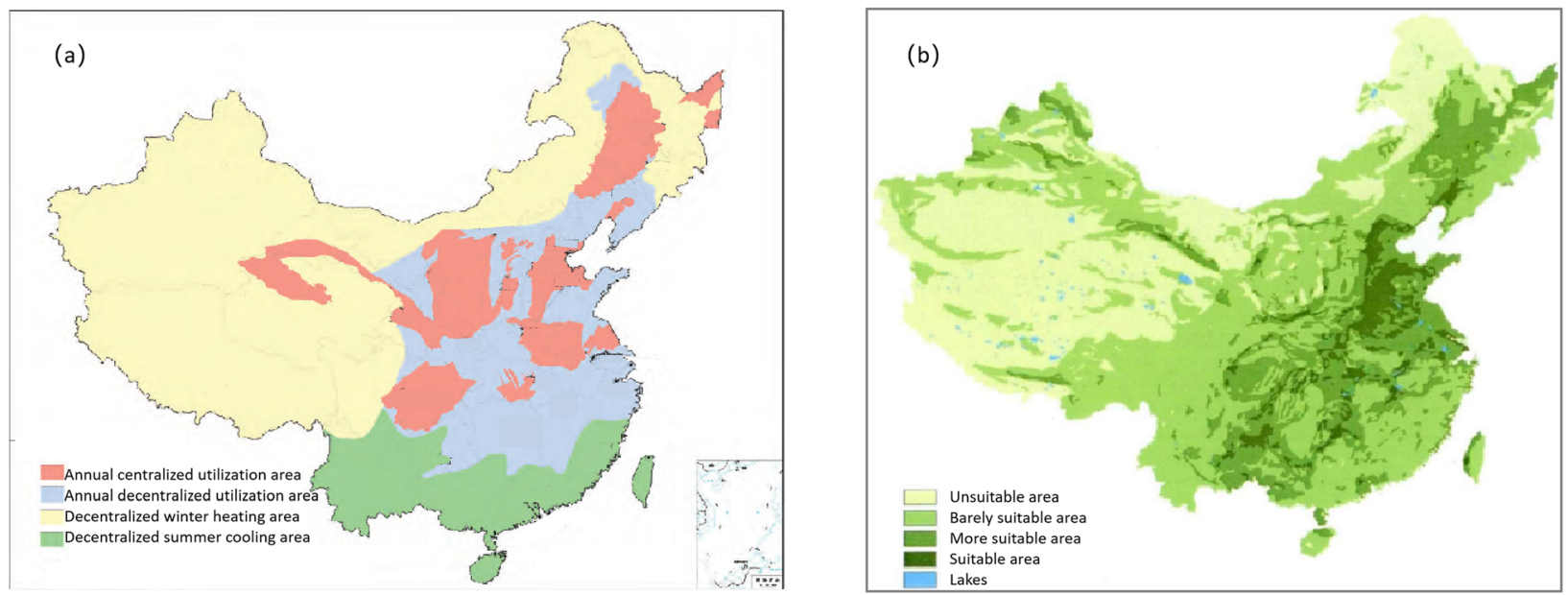

Fig. 5 Division of geothermal energy development and use in China [5]. a Division of shallow geothermal energy development and utilization zones in China; b Application suitability map of groundwater source heat pumps in China

\subsection{Development history and utilization status of shallow GSHPs}

\subsubsection{Development history of GSHPs}

(1) Initial stage (1980s early twenty-first century): At the end of the last century, the special topic of heat pumps was added to the national HVAC annual conference and other academic conferences. Afterwards, GSHPs began to be gradually understood and valued by scientific researchers.
(2) Promotion stage (2000-2004): In the new century, the application of GSHPs in China became ever more extensive, with rapid growth in relevant academic achievement including patents and papers. However, many problems were exposed in the applications because of the lack of engineering experience, specifications and standards.

(3) Rapid growth stage (2005-2013): with China's increasing attention on energy conservation and emission reduction, GSHPs began to develop

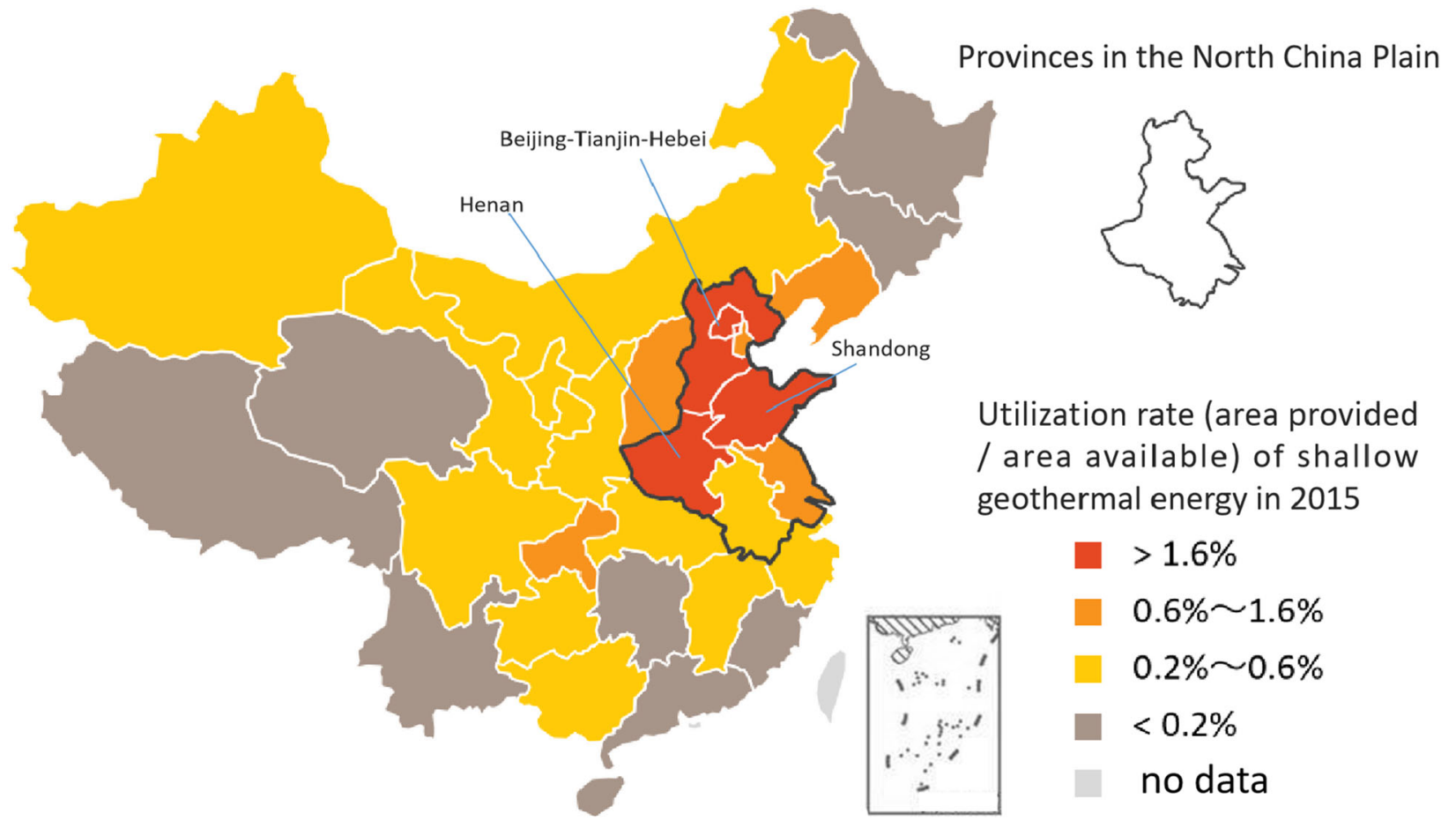

Fig. 6 Utilization rate of shallow geothermal energy [6] 
rapidly because of their environmentally friendly advantages. Equipment manufacturers and patented technologies have increased significantly. Moreover, relevant policies and standards were put forward and constantly improved.

(4) Stable development stage (2014-present): In recent years, the development of ground water source heat pumps has been restricted because of the overexploitation of groundwater in many areas, while there has been a huge demand for renewable energy technologies in response to the air pollution control plan. Thus, because of the influence of these two aspects, GSHPs have entered a stable development stage [3].

\subsubsection{Utilization status}

By the end of 2017, the total installed capacity of GSHPs in China was 20,000 MW, ranking first in the world. The annual use of shallow geothermal energy was equivalent to 19 million tons of standard coal, and the energy supply area was more than 500 million square meters [4]. At present, GSHPs account for more than $60 \%$ of geothermal heating use in China.

Currently, shallow geothermal energy resources are mainly used for building heating and cooling. The groundwater source heat pump systems in the 31 provincial capitals in China have a total cooling area of 1 billion square meters, and a heating area of 622 million square meters. The underground pipe GSHP systems have a total cooling area of 8.26 billion square meters and a heating area of 9.07 billion square meters. On the user side, the total area equipped with GSHPs for cooling supply is 8.21 billion square meters, and 8.86 billion square meters for heating [5]. Figure 4 shows the annual variation of energy supply area of GSHPs in China from 2000 to 2020.

In terms of use of shallow geothermal energy, as shown in Fig. 5, the North China Plain has achieved remarkable results, with Beijing-Tianjin-Hebei, Shandong, and Henan Provinces accounting for 5 of the top 6 in China [6]. However, even though Hebei ranks first, its use rate is still under 3\%, so there is great development potential. The utilization rate of shallow geothermal energy in China is shown in Fig. 6.

\section{Engineering cases and analysis of shallow GSHPs}

\subsection{Typical engineering cases of shallow GSHPs}

\subsubsection{China's first large scale GSHP project: Beijing Jiahe} liyuan-2000

In November 1998, experts from China and the United States jointly formulated the "US soil-gas ground-source heat pump technology cooperation promotion plan in China" in Washington, USA. The plan was used in the

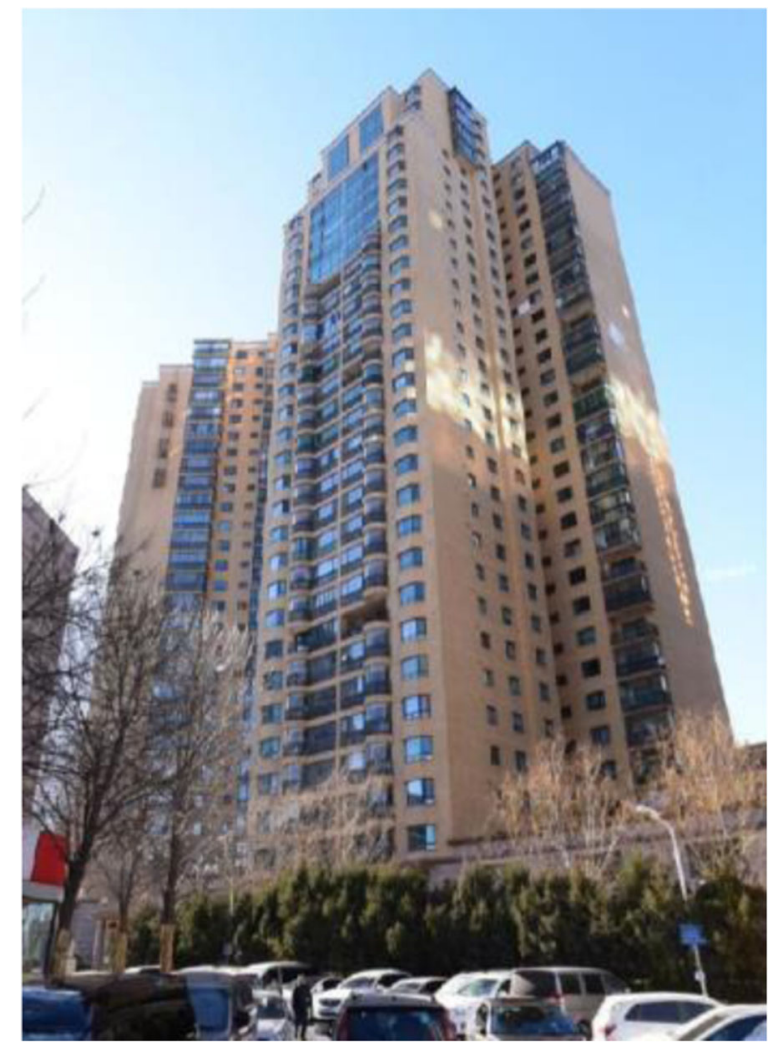

Fig. 7 Beijing Jiahe Liyuan International Apartment

cold climate zone of northern China, the temperate climate zone of the Yangtze River Basin, and the subtropical climate in the south. Each district built a GSHP demonstration project. Among them, the Beijing Jiahe Liyuan International Apartment (as shown in Fig. 7) was put into trial operation in 2000 with an air-conditioning area of 70,000 square meters. The project was designed by Tsinghua University with guidance from American experts. It is the first documented large-scale GSHP project in China, and was also the GSHP system with the

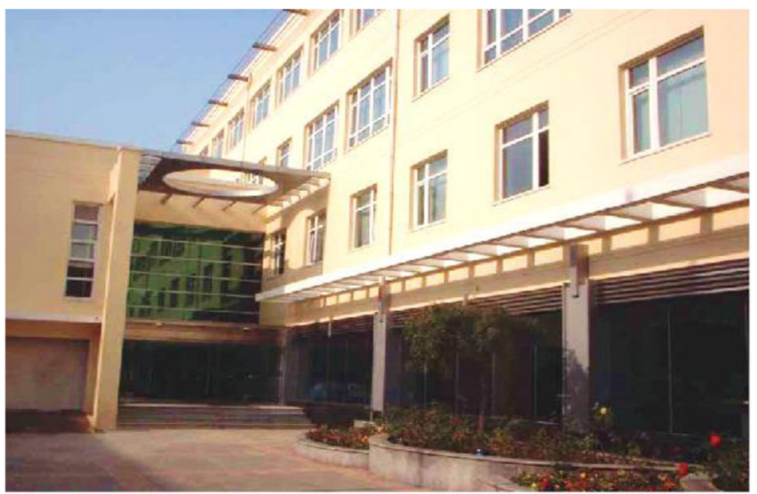

Fig. 8 Office building of the Tianjin Meijiang ecological community 

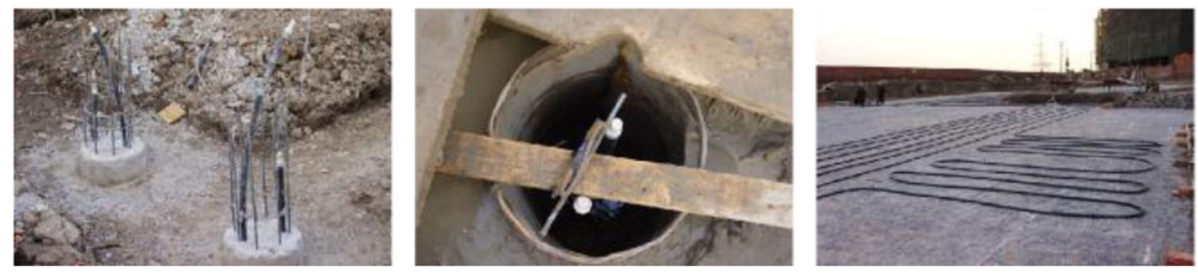

Fig. 9 Buried pipe forms. a Pile; b Vertical; c Horizontal

highest single building height and the second highest building area in the world at that time.

The project adopts four 160-m-deep wells as the cold and heat source, coupled with a groundwater heat pump unit produced by the American Trane Company. The initial investment of the system is similar to that of a traditional central air conditioning system, while the annual operating cost is reduced by $43.6 \%$ [7].

\subsubsection{Tianjin's first GSHP project: Tianjin Meijiang ecological community-2003}

The first practical GSHP project in Tianjin was designed by our research group and installed at the office building of the Tianjin Meijiang ecological community (as shown in Fig. 8). It was planned, researched, and tested in 2001. The construction area of the project is 3715 square meters and since late 2003, the system has been running continuously for over 17 years.

The project uses soil as the cold and heat source, and the underground heat exchanger contains pile, vertical and horizontal buried pipes, as shown in Fig. 9.

The project contains an automatic monitoring system to collect and record the underground and ground temperatures, flowrates, electric power consumption, and other key operating parameters during the operating period. The monitoring system has accumulated a wealth of real operational data, and the results show that the GSHP system has met the design requirements with stable performance and good effect during intermittent operation of heating in winter and cooling in summer. In winter, the indoor temperature is $18-22^{\circ} \mathrm{C}$, and in summer it is about $25^{\circ} \mathrm{C}$ [8]. The ground temperature near the ground heat exchanger is higher in winter and lower in summer than the ground air temperatures, which enables the heat pump unit to operate at high efficiency.

The economy of the $3715 \mathrm{~m}^{2}$ GSHP demonstration project in Meijiang ecological community in Tianjin has been calculated in detail [9]. The results prove that the GSHP technology has great energy-saving advantages compared with several conventional heating and air-conditioning modes such as coal, natural gas and electricity. However, the data shows that the heat load of the system in summer is about 2.56 times of that in winter and the accumulated heat output is 2.96 times of the accumulated heat absorption. Specifically, the heat output is $2.85 \times 10^{8} \mathrm{~kJ}$ more than that of the heat absorption resulting in the imbalance of the cold and heat of the underground soil and the rise of the underground soil temperature. An increase of underground soil temperature by $2-4{ }^{\circ} \mathrm{C}$ after 1 year of operation has been observed. This is conducive to the heat absorption operation of the heat pump system in winter, but not to the heat removal operation in summer [9]. The long-term imbalance of soil heat results in a continuous increase or decrease of soil temperature, which not only reduces the operational performance of the system, but also has a great impact on the ecological environment.

To help solve the problem of unbalanced cold and heat, a "hybrid system" [10] can be used. For example, an "underground buried pipe cooling tower" is suitable for situations where heat discharged is greater than heat absorbed, whereas the mode of "underground pipe auxiliary heat source" is applicable to situations with greater heat absorption than heat output, so the ground temperature can be balanced.

\subsubsection{China's first GSHP and ice storage project: Beijing Tianchuang Shiyuan Building-2002}

The Tianchuang Shiyuan building as shown in Fig. 10 is located in Chaoyang District, Beijing. The air conditioning area of the large commercial facilities at the bottom of the building is about 40,000 square meters, with a cooling design load of $6.05 \mathrm{MW}$ and a heat load of 4 MW. The project adopts the GSHP and ice storage air

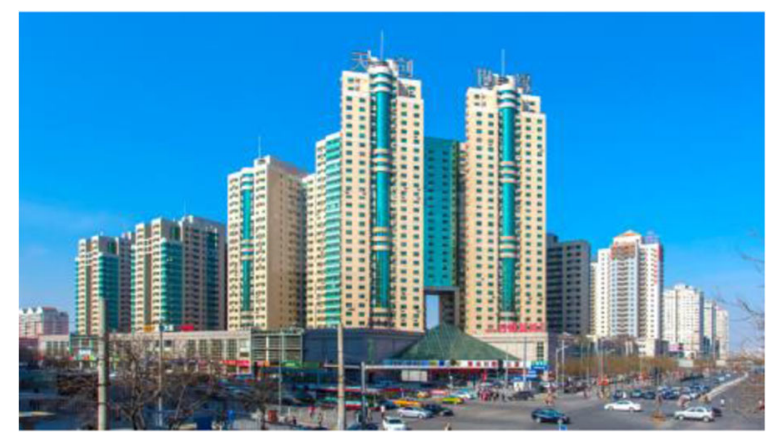

Fig. 10 Tianchuang Shiyuan building 


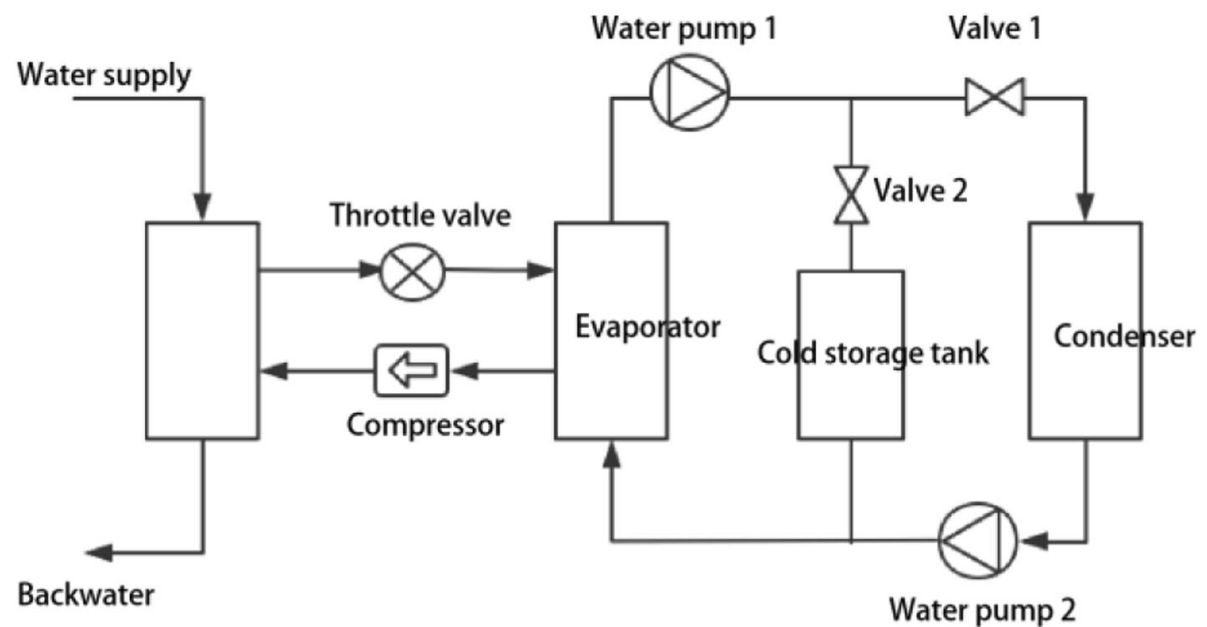

Fig. 11 The schematic diagram of GSHP coupled with ice storage system

conditioning system designed by the China Academy of Building Sciences [11]. It was completed in September 2002, and is the first project to adopt this kind of system in China.

In the hybrid system of GSHP with ice storage equipment, a cold storage tank was added in parallel with the evaporator and end heat exchanger in the traditional heat pump system. This can realize four operational modes of conventional cooling cycle, cold storage cycle, combined cooling cycle, and single cold storage and supply cycle. The optimal scheduling among different operation modes can effectively reduce the power consumption of refrigeration equipment, as well as reducing the operational cost of the air conditioning system during the peak period Fig. 11.

Theoretical calculation indicated that if only the heat pump system were used, eleven wells would be needed and the groundwater consumption would be quite large. However, in the hybrid system operational mode, 7 wells are sufficient for energy supply, which reduces system power consumption. With the support of the electric power department and electric power subsidy of 2.4 million yuan, the actual project investment was only 560, 000 yuan. Compared with the conventional system, the annual operational cost can be reduced by 1.58 million yuan, showing a remarkable economic benefit.

\subsubsection{China's largest GSHP project: Beijing Daxing international airport-2019}

Beijing Daxing International Airport, as shown in Fig. 12, was opened in September 2019. It is the largest single airport terminal in the world and has the largest GSHP system in China. The system contains two heating stations with energy supply from the GSHPs, and the building area of the heating stations alone exceeds 17,000 square meters.

The buried pipes of the system are located in the flood storage and the detention area of the airport, as shown in Fig. 13. The total length of buried pipes is $10,680 \mathrm{~m}$, and the buried area is 267,000 square meters. The heating and cooling capacities of the system are $54.2 \mathrm{MW}$ and 48.8 MW, respectively. The energy supply area of the system in

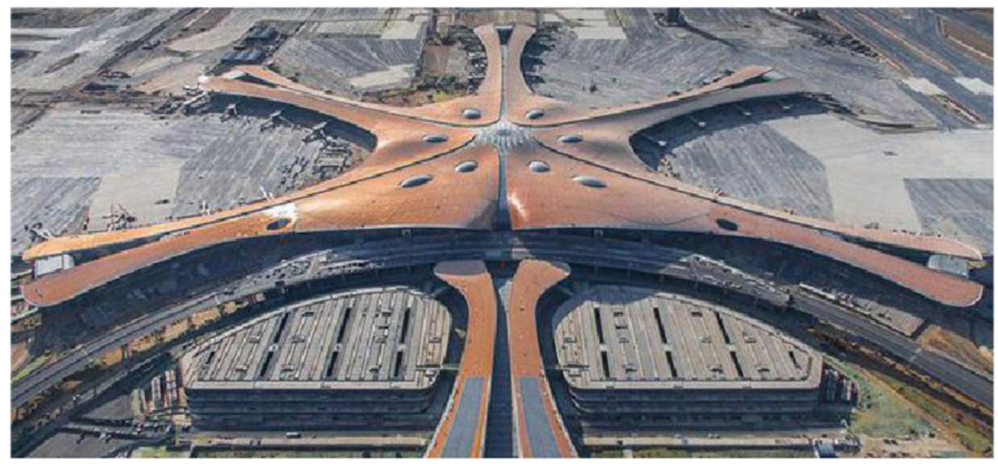

Fig. 12 Beijing Daxing International Airport 


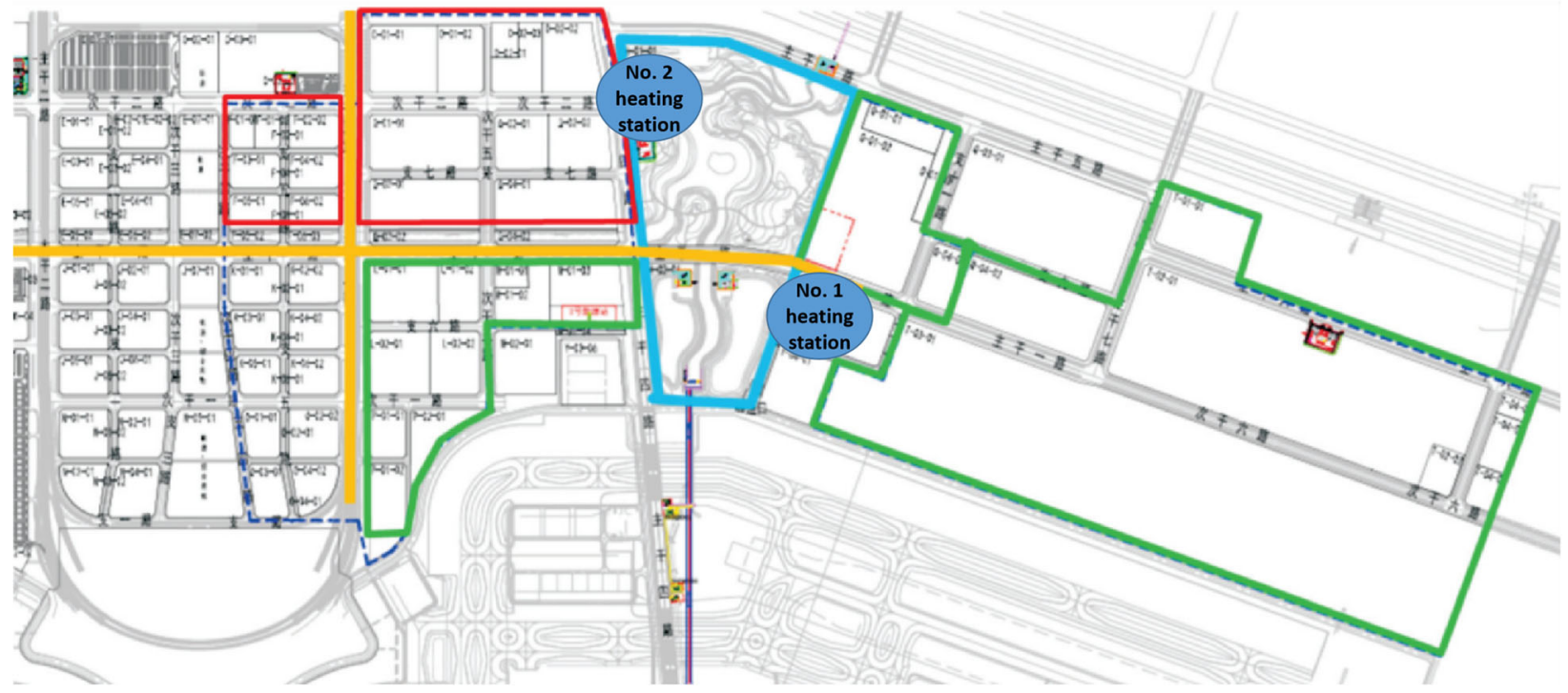

Fig. 13 Buried pipe layout area [12]

2018 was about 1 million square meters, and the planning area is about 2.5 million square meters [12].

The new airport requires the temperature of the heating water outlet of the equipment to reach $50{ }^{\circ} \mathrm{C}$ while the operating pressure difference of the unit is relatively large. Thus, the system adopts the technology of full falling film variable frequency centrifugal heat pump units, as shown in Fig. 14.

In addition, the system couples with flue gas waste heat, sewage waste heat and other renewable energy, to form a multi-energy complementary GSHP system, achieving the construction goal of $10 \%$ renewable energy utilization.

\subsubsection{The first bedrock GSHP project in Beijing: Tianhu international conference hotel-2004}

The GSHP project of the Beijing Tianhu International Conference Hotel is the first demonstration project carried out by the Beijing Development and Reform Commission in a bedrock area. Through the implementation of the project, the technical problems of GSHP system in a bedrock area are solved, while the original air conditioning system of the hotel is renovated to reduce its operational cost and improve the atmospheric environment of the Qinglong Lake area. The total construction area of the project is 40,000 square meters, and a total of 218 vertical buried tube

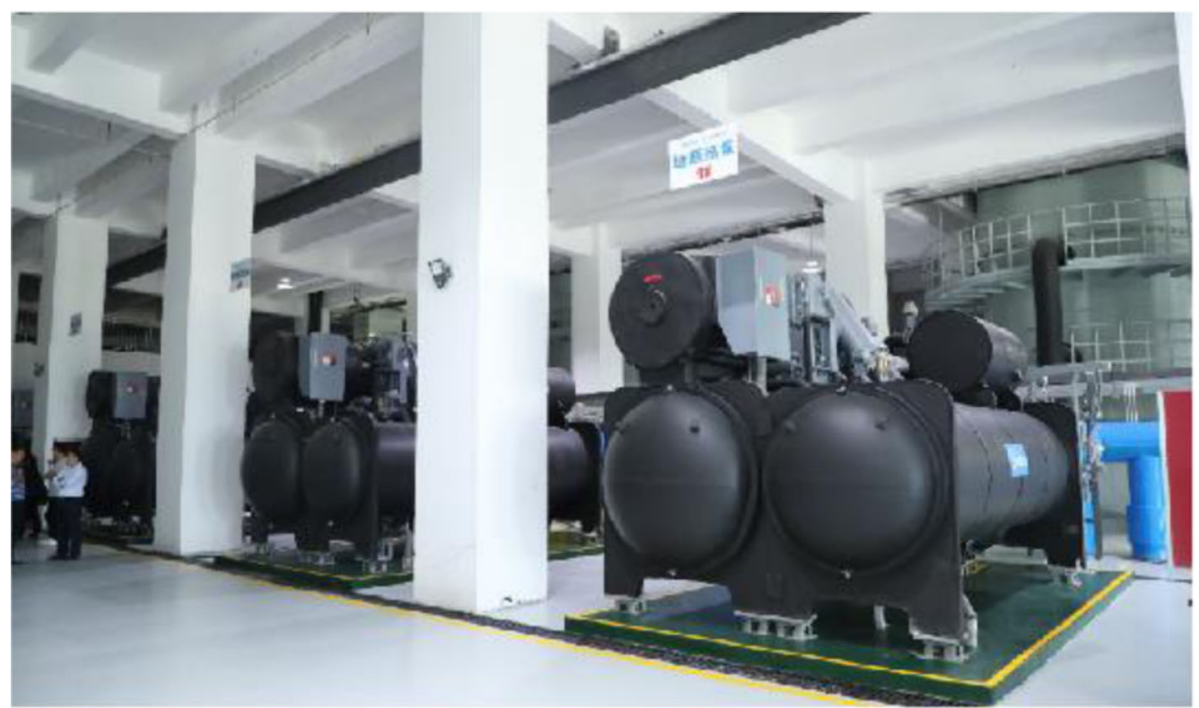

Fig. 14 Full falling film variable frequency centrifugal heat pump units 


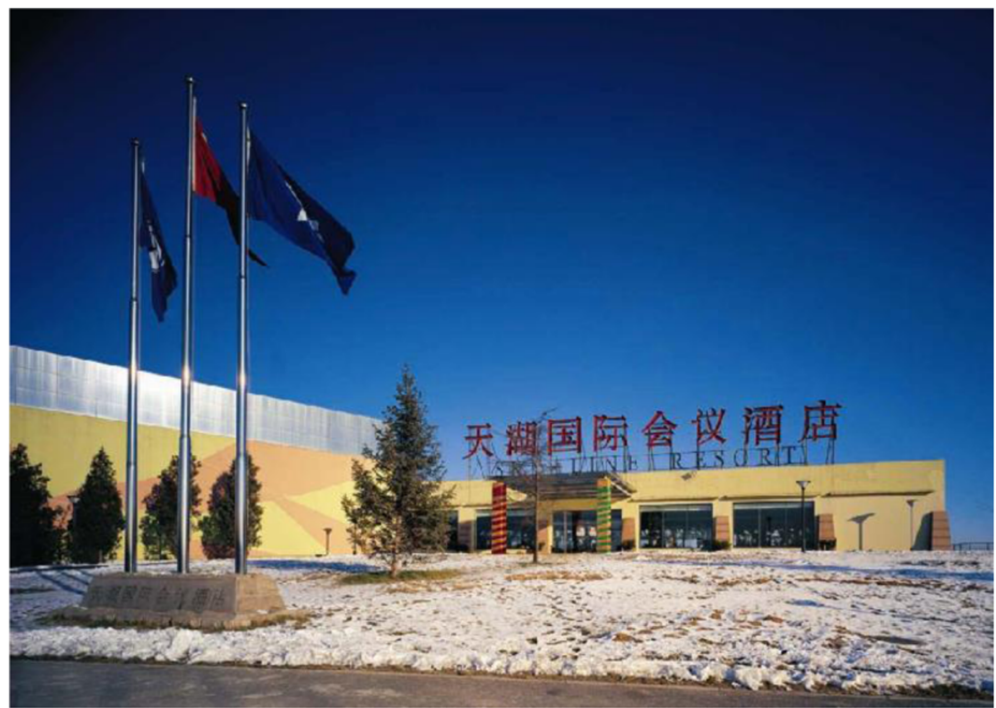

Fig. 15 Beijing Tianhu International Conference Hotel

heat exchangers are buried with a drilling depth of $120 \mathrm{~m}$ (Fig. 15).

The energy consumption of the project was quite high in the initial operational period. According to the site analysis of the construction company, the operational strategy of the circulating pump was adjusted, and the hydraulic balance at the end was improved. After the adjustment, the energy consumption is reduced by $30 \%$. Compared with the original air-conditioning system, the new system can save 2.5 million yuan of annual operational cost for the hotel, and the initial investment of the project can be recovered within 4 years. At the same time, hundreds of tons of $\mathrm{SO}_{2}, \mathrm{NO}_{\mathrm{x}}$ and $\mathrm{CO}_{2}$ emissions can be reduced each year [13].

\subsubsection{The first underground GSHP project in Beijing: Beijing contemporary world city-2006}

The Beijing contemporary world city MoMA, as shown in Fig. 16, is located in the Dongcheng District with a total construction area of 220,000 square meters, including 8 residential buildings and 1 hotel. The buildings are connected by steel structure corridors and were listed as one of "the world's top 10 architectural wonders" by Time Magazine in 2007. It adopted a ceiling radiant cooling and heating system and displacement ventilation system, with the largest GSHP system in the world at that time.

The special feature of the GSHP system is that all the buried pipes are located below the underground

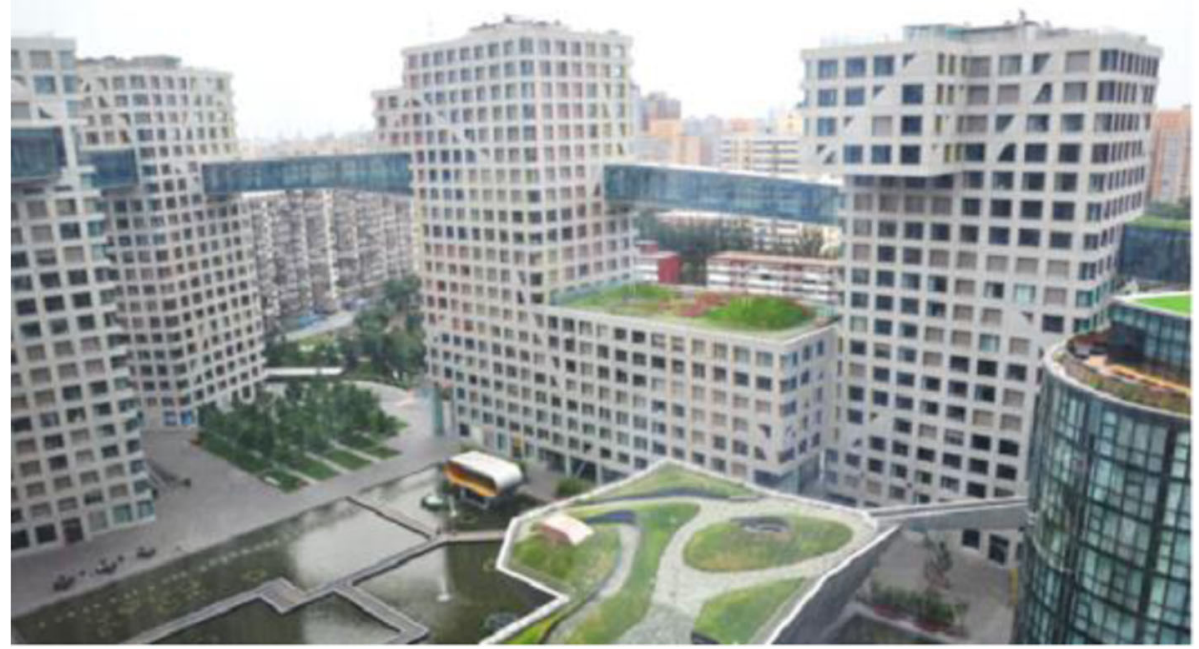

Fig. 16 Beijing contemporary world city 


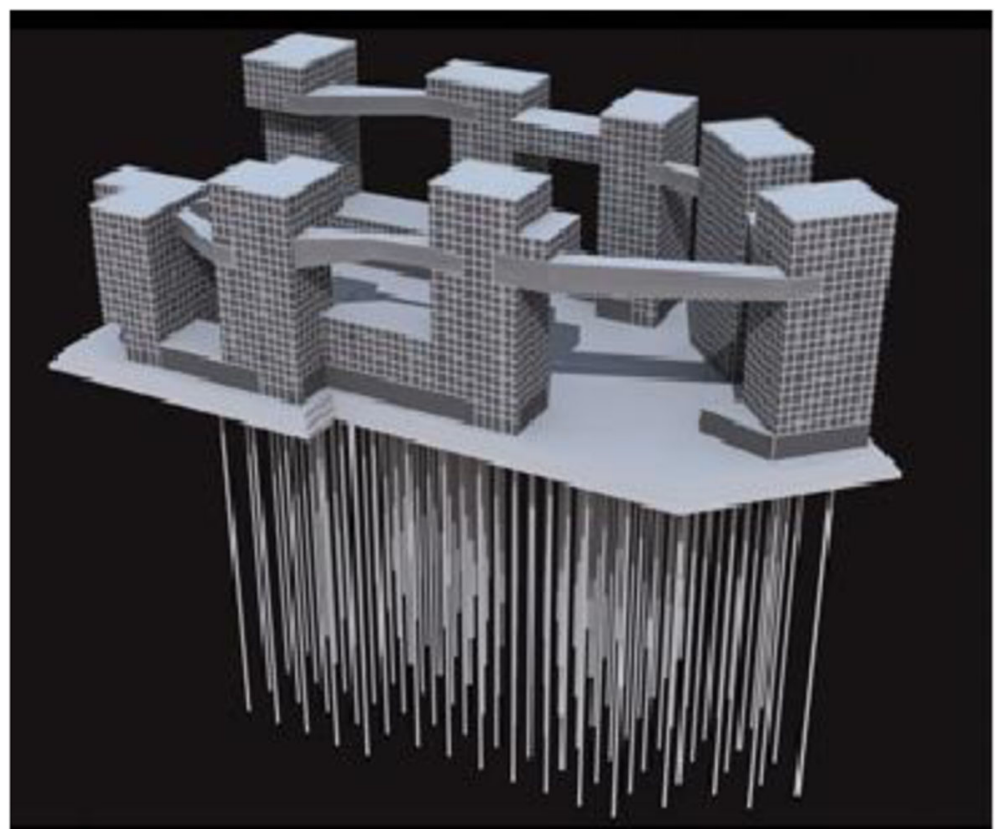

Fig. 17 Buried pipes of GSHP system in Beijing contemporary world city

garage on the second floor (as schematically shown in Fig. 17), including 655 vertical ground tube heat exchangers with a depth of $100 \mathrm{~m}$. In the design and construction of the system, many breakthrough problems were solved such as waterproofing of the soil heat exchanger through the bottom plate and the disturbance of the heat exchange hole of the soil heat exchanger on the base during construction. The system also won the 2006 American "popular science" Engineering Award with the title of the largest geothermal energy supply building.
3.1.7 GSHPs assist Shanghai world expo: expo axis-2010

The Expo Axis and underground complex project (as shown in Fig. 18) is located at the side of the Huangpu River in Shanghai and is the main access to the Expo 2010 Shanghai. It is around $1000 \mathrm{~m}$ long from north to south and 80 to $110 \mathrm{~m}$ wide from east to west. It has two floors underground and two floors above ground, with a total construction area of 250,000 square meters. The project adopts a composite system of GSHP, river water source heat pump, and water chiller. The buried pipes are arranged in the cast-in-place piles to form pile buried pipes.

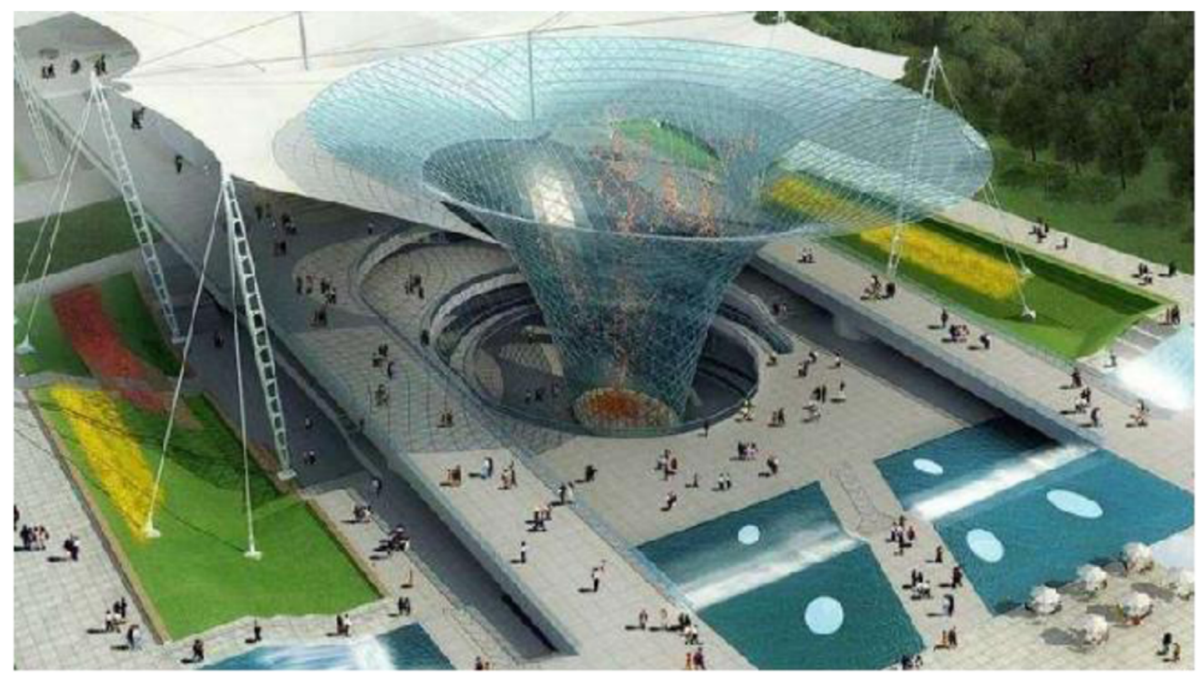

Fig. 18 Expo Axis and underground complex project 


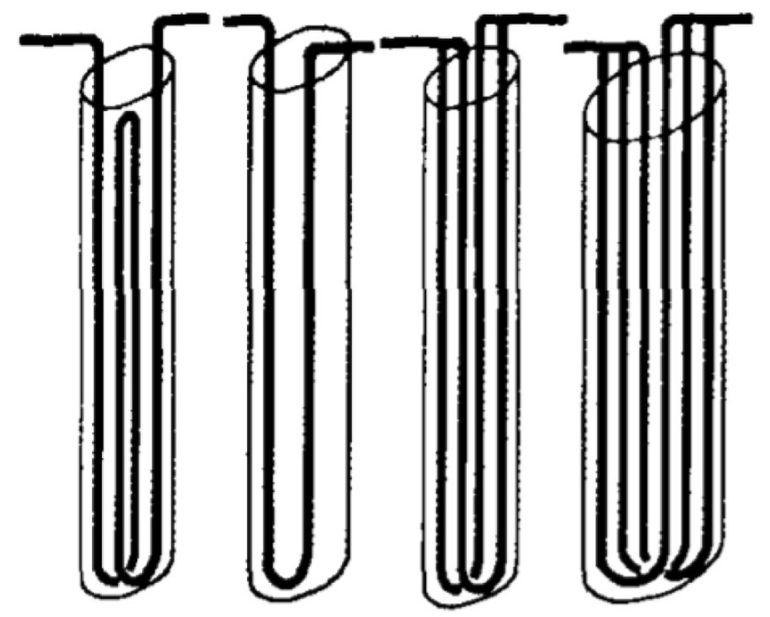

Fig. 19 Different types of heat exchangers [14]. a W-type; b Single U-type; c Parallel double-U-type; $\mathbf{d}$ Parallel three-U-type

During the design, thermal response tests [14] were performed on W-type, single U-type, parallel double-Utype, and parallel three-U-type heat exchangers, as shown in Fig. 19. The W-type heat exchanger was selected for its comprehensive heat exchange effect and cost. The project has a total of 6000 piles and buried pipes, and the buried pipe GSHP system bears $30 \%$ of the total load.

It is estimated that the project can save 5.63 million $\mathrm{kW} \cdot \mathrm{h}$ of electricity and reduce carbon emissions by 5629 tons per year. The building has won many awards, such as the Luban Award of China Construction Project and the global ecological architecture award.

\subsubsection{Summary of typical engineering cases of shallow GSHPS}

Table 1 summarizes the features of above typical engineering cases of shallow GSHPs, including GSHP type, capacity and building area.

\subsection{Characteristic analysis of GSHPs}

According to the engineering cases in the previous section, the GSHPs have the following advantages:
(1) One machine can be used for many purposes and has a wide range of applications. GSHP systems can be used for heating, air conditioning, and domestic hot water. Thus, one set of systems can replace the original two sets of boiler or air conditioning systems. GSHP systems can be used in hotels, shopping malls, office buildings, schools and other buildings to improve building appearance and the style of the city.

(2) Good economic and energy-saving benefits. Because of the relatively stable temperature of ground energy or shallow geothermal resources, GSHP systems have higher operational efficiency and lower operating cost than traditional air conditioning systems.

(3) Significant environmental benefits. GSHPs are clean energy systems with fewer pollutant emissions. The operation of the devices uses electricity, so there is no combustion process, no smoke exhaust, no waste, no groundwater extraction, and no damage to groundwater resources, etc.

(4) No surface land occupation. The heat exchanger of GSHPs is buried underground and can be arranged around buildings, such as under gardens, lawns, farmland, lakes or pools in soil, rock or an underground water layer, while the pipes can be buried in concrete foundation piles and do not occupy surface area.

However, GSHPs have the problem of heat and cold imbalance. In the south, cooling is the main operational mode, which injects heat into the ground all the year round. While in the north, there is a large demand for heating in winter, and a large amount of heat is absorbed from the soil. After long-term operation, the soil temperature can become unbalanced and system efficiency reduced, while affecting the surrounding ecology. In addition, there must be enough area/s for drilling and pipe laying.

\section{Development trend of shallow GSHPs}

Because of the features of high efficiency and low carbon emission, as one of the typical geothermal technologies,

Table 1 Features of typical engineering projects

\begin{tabular}{|c|c|c|c|}
\hline Name of projects & GSHP type & Capacity (MW) & Building area $\left(\mathrm{m}^{2}\right)$ \\
\hline Beijing Jiahe liyuan & Groundwater heat pump & - & 70,000 \\
\hline Tianjin Meijiang ecological community & Ground-coupled heat pump & 0.32 & 3715 \\
\hline Beijing Tianchuang Shiyuan Building & Groundwater heat pump & 6.05 & 40,000 \\
\hline Beijing Daxing international airport & Ground-coupled heat pump & 54.2 & 17,000 \\
\hline Tianhu International Conference hotel & Ground-coupled heat pump & - & 40.000 \\
\hline Beijing contemporary world city & Ground-coupled heat pump & 4.8 & 220,000 \\
\hline Expo axis & Ground-coupled heat pump & - & 250,000 \\
\hline
\end{tabular}



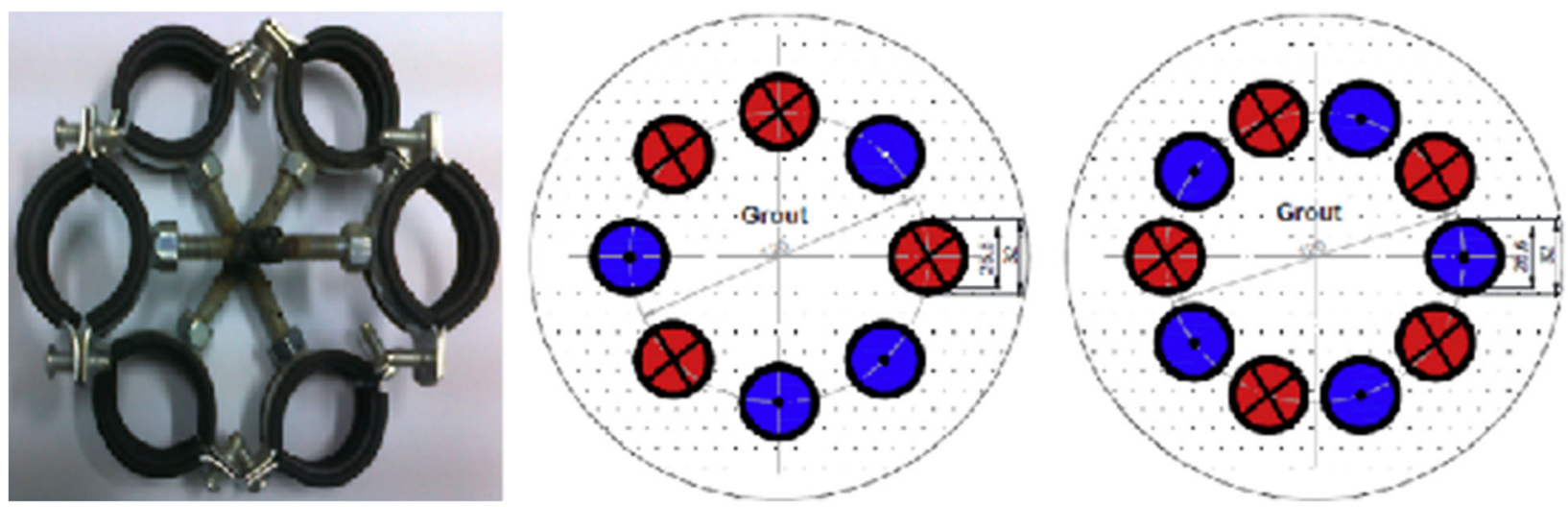

Fig. 20 Multi-pipe borehole heat exchangers [16]

GSHPs have been widely used in various buildings. In China, the annual average growth rate of geothermal use rose to $18.7 \%$ from 2010 to 2014 [15]. To promote the energy-saving and environmental benefits of GSHP systems, it is necessary to pay attention to the existing problems, especially energy imbalance, which has negative effects on system efficiency and stability during long-term operation. In addition, shallow GSHPs have large numbers of boreholes and take up large floor area, which can be decreased by the optimization of the heat transfer performance of the heat exchanger. At present, the new technologies of heat transfer enhancement of buried pipes include increasing heat exchange area and using phase change enhancement. Finally, GSHPs coupled with various energy sources are a promising approach to promote the applications of GSHPs.

\subsection{Hybrid systems to solve the problem of uneven cooling and heating}

The promotion of GSHPs is promising because of its energy saving and environmental protection. However, if the wide application of GSHPs seriously affects the ecological environment, it would be counter to the original intention behind their use. To solve the problem of soil cold and heat imbalance, environmental impact assessment and geological exploration should be carried out before the implementation of the project. In addition, in the design stage, the cooling and heating loads should be dynamically calculated throughout the year, proper hole spacing should be designed, and the depth of borehole heat exchangers should be appropriately increased, etc. During the implementation stage, the number of soil heat exchangers and the distance between soil heat exchangers should be properly increased based on the hybrid system according to the specific situation.

In areas with large cooling load, such as Beijing, Tianjin and southern China, reasonable use of waste heat from condenser (such as production of domestic hot water) can be adopted to reduce the heat discharged into the ground and avoid excessive ground temperature rise. At the same time, appropriate structural measures such as heat insulation and shading should be taken in the maintenance structure of buildings to reduce the thermal impact of
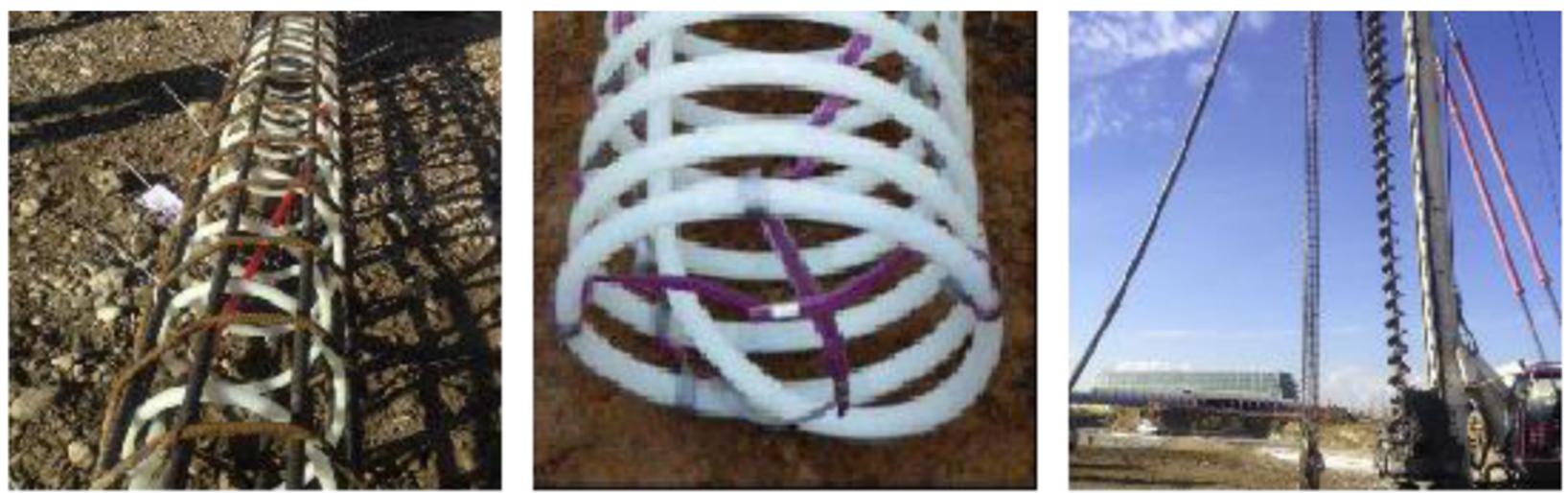

Fig. 21 Spiral borehole heat exchanger [16] 

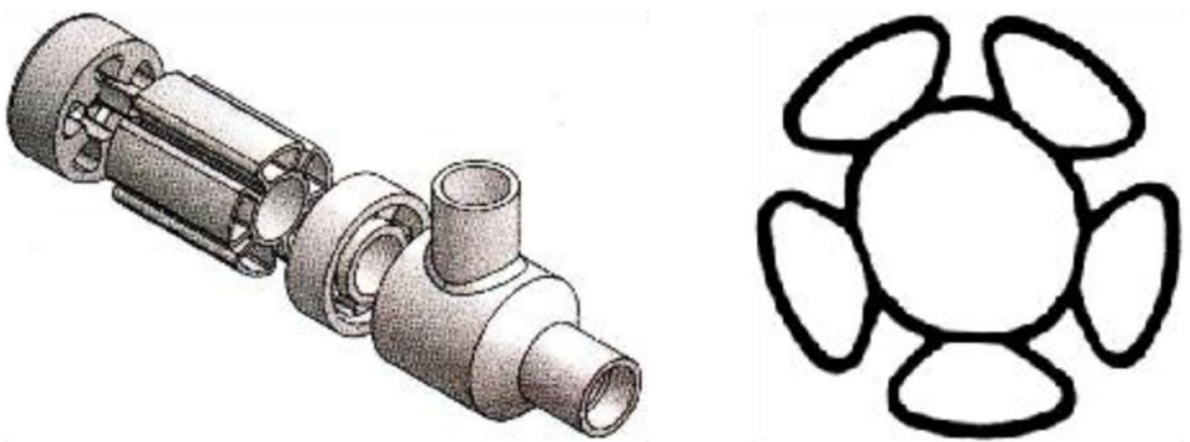

Fig. 22 New type of coaxial borehole heat exchangers [16]. a Structural diagram; b cross section of pipe

the external environment on buildings in summer. In areas with large heat load, auxiliary heating measures (e.g., rational use of solar energy, industrial waste heat, etc.) can be adopted in winter to reduce the heat absorption from the soil. Such approaches can slow down the decrease of ground temperature, balance the yearly heat absorption and discharge, and realize the sustainable use of a GSHP system [10].

\subsection{Ground heat exchangers with increased heat transfer area}

The larger the heat exchange area has, the better the heat transfer effect is. Therefore, the heat transfer performance can be improved by increasing the heat transfer area. In this paper, three kinds of advanced ground heat exchangers are studied: multi-pipe borehole heat exchangers, spiral borehole heat exchangers, and coaxial

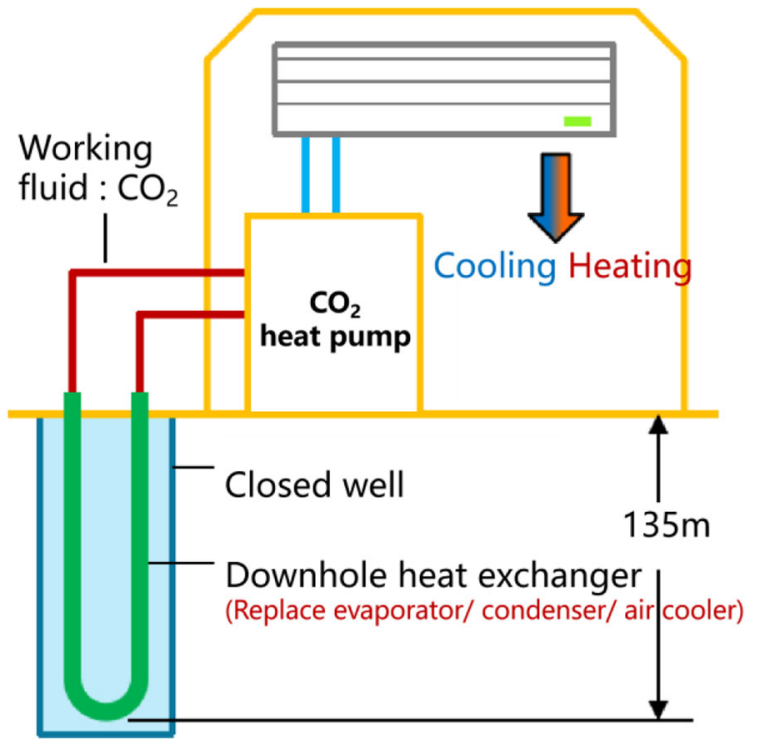

Fig. 23 Direct expansion $\mathrm{CO}_{2}$ heat pump system borehole heat exchangers [16], as shown in Figs. 20, 21 and 22 respectively.

\section{(1) Multi-pipe borehole heat exchangers}

The heat transfer structure of a multi-pipe borehole heat exchanger is simple, and is composed of at least three U-pipes connected in one borehole. Reference [17] tested a $3 \mathrm{U}$ - tube borehole heat exchanger by the thermal response test (TRT), while the heat transfer effect of $4 \mathrm{U}$-tube and $5 \mathrm{U}$-tube borehole heat exchangers were studied by numerical simulation. Under the designed experimental conditions, the heat transfer rate of a $3 \mathrm{U}$ tube is $25 \%$ higher than that of single U-tube. However, the simulation results show that the performance improvement of $4 \mathrm{U}$ and $5 \mathrm{U}$-tube borehole heat exchangers is not significant.

\section{(2) Spiral borehole heat exchangers}

The heat transfer area of a spiral buried tube as shown in Fig. 21, is larger than that of conventional U-tube. To obtain enough structural strength, it should be fixed onto the reinforcing frame during installation to increase its outer diameter. Compared with a double U-tube, the growth rate of the heat transfer rate of spiral borehole heat exchangers is as high as $40 \%$ at peak load. In [18], the influence of different axial thermal conductivity parameters on pile design was studied. In addition, thermal response tests were carried out to verify the model. The simulation results showed that the peak load can be increased by about $14 \%$ when the pitch is reduced by $50 \%$.

(3) New coaxial borehole heat exchangers

High-density polyethylene (HDPE) is used as the material for the new type of coaxial borehole heat exchangers. The outer diameter of the pipe is $84 \mathrm{~mm}$, and the structure diagram and cross section of the pipe are shown in Fig. 22. 


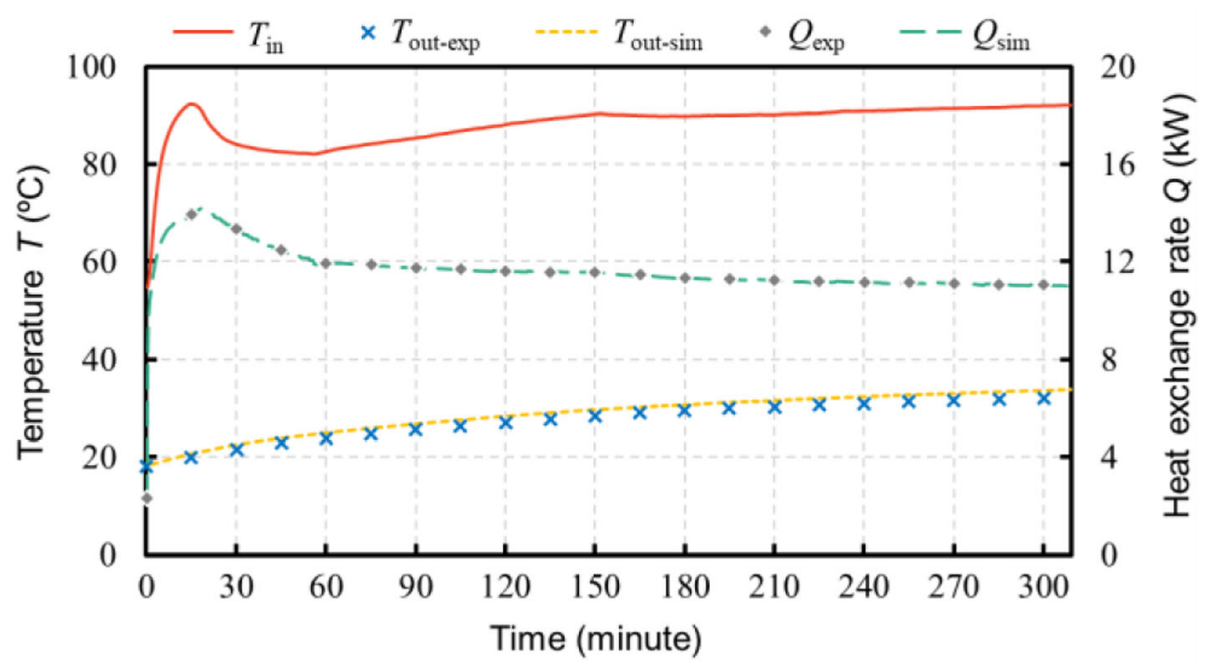

Fig. 24 Model simulation results

The new type of coaxial borehole heat exchangers can be transported in rolls, and the original construction technology can be retained to directly replace the traditional double-U-type borehole heat exchangers. Its main advantages are: first, the heat exchange rate at the initial stage of operation is increased by over 30\% compared with the double- $U$ borehole heat exchangers. This is suitable for intermittent operation conditions; and second, the pressure drop is significantly reduced, with an average reduction of around $60 \%$.

\subsection{Direct expansion $\mathrm{CO}_{2}$ heat pump systems based on phase change downhole heat exchangers}

The heat transfer capacity of ground heat exchangers based on the phase change principle is clearly higher than that of conventional ground heat exchangers. A direct expansion $\mathrm{CO}_{2}$ heat pump system with $\mathrm{CO}_{2}$ as phase change fluid is shown in Fig. 23. Its main advantages are:

(1) $\mathrm{CO}_{2}$ is an environmental protection natural working fluid, which will not pollute the underground environment.

(2) Phase change heat transfer (heating condition) is the main mechanism in the heat exchanger, and the spontaneous natural convection in the well also enhances heat transfer. Thus, both can effectively improve heat transfer performance.

(3) The heat exchange rate of a single well is high, so the construction area is smaller than other geothermal systems.

(4) The circulating pump on the source side is not needed, and this can reduce initial investment and operational cost.

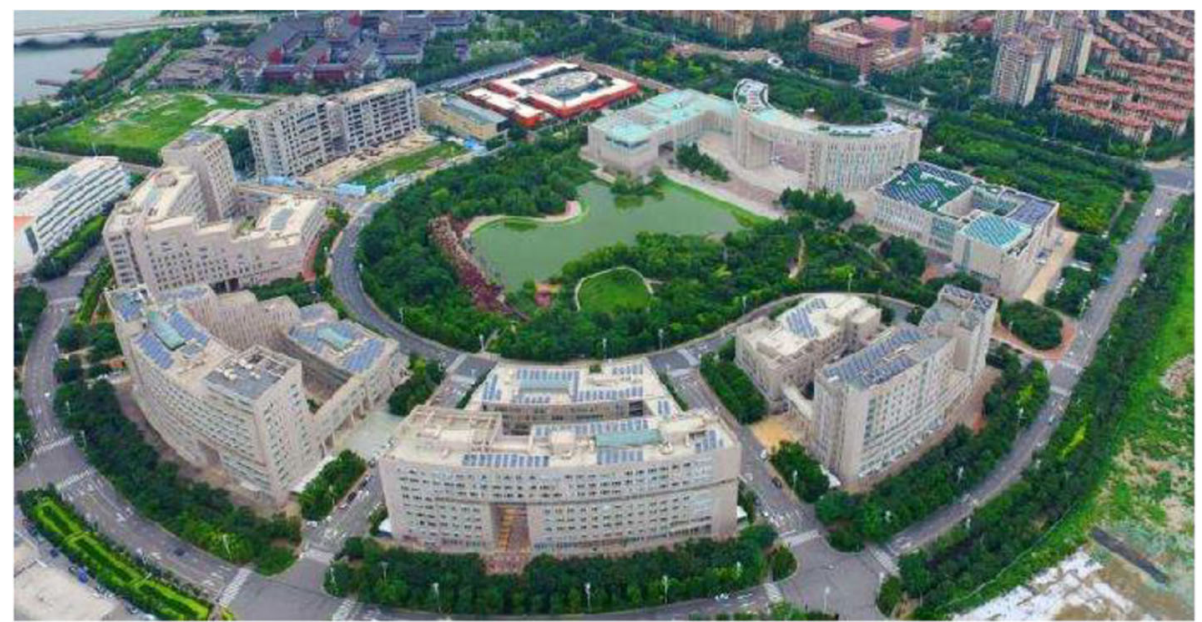

Fig. 25 Sino-Singapore Tianjin eco-city 
Table 2 Energy technology of the eco-city

\begin{tabular}{llll}
\hline Equipment type & Cooling / storage capacity & Heating / heat storage capacity & Number of sets \\
\hline GSHP & $3550 \mathrm{~kW}$ & $4100 \mathrm{~kW}$ & 2 \\
Energy storage tank & $6075 \mathrm{~kW} \cdot \mathrm{h}$ & $11,425 \mathrm{~kW} \cdot \mathrm{h}$ & $1472 \mathrm{~kW}$ \\
Combined cooling, heating and power supply & $1465 \mathrm{~kW}$ & - & 1 \\
Electric refrigeration & $4100 \mathrm{~kW}$ & - & 2 \\
\hline
\end{tabular}

(5) The outlet water temperature is high, up to $90{ }^{\circ} \mathrm{C}$, which is suitable for the renovation of traditional radiator heating buildings.

(6) The heat exchanger is convenient for maintenance and transformation.

The test results of the refrigeration condition are as follows:

(1) The COP of the unit can reach 3.9, which can be $50 \%$ more than with the traditional air-cooled $\mathrm{CO}_{2}$ unit.

(2) The heat transfer capacity of the effective section of the underground heat exchanger can reach more than $200 \mathrm{~W} / \mathrm{m}$.

(3) There is no poor oil return problem.

Based on the thermal resistance and heat capacity network method (TRCM), a three-dimensional unsteady heat transfer model is constructed. The heat transfer models of convection heat transfer in the tube, heat conduction in the borehole and natural convection in the well are embedded, so dynamic heat transfer simulation under supercritical condition can be realized Fig. 24 .

The model has been validated by experiment. The average relative error of heat transfer is less than $2.3 \%$, and the calulation speed is increased by dozens of times compared with the traditional CFD simulation.

\subsection{GSHPs and multi-energy coupling}

Despite the advantages, further promotion of GSHP systems is affected by the required large investment and floor area. Cold storage and heat storage systems have the function of transferring peak cooling and heating load and balancing peak valley difference [19]. Proper coupling between cold or heat storage systems and GSHP systems can effectively reduce the scale of the GSHP systems and make full use of the low-voltage power grid to improve the economic efficiency of the projects [20]. To promote the application of GSHPs, it is necessary to research the optimal configuration of GSHP multi-energy use coupling systems.

Sino-Singapore Tianjin eco-city is a strategic cooperation project by the governments of China and Singapore to improve the ecological environment and building an ecological civilization. It is located in the Binhai New District of Tianjin. The national animation Park in the eco-city (as shown in Fig. 25), contains 6 buildings, with a total design energy supply area of 240, 000 square meters, a cooling load of $21 \mathrm{MW}$ and a heating load of $14 \mathrm{MW}$.

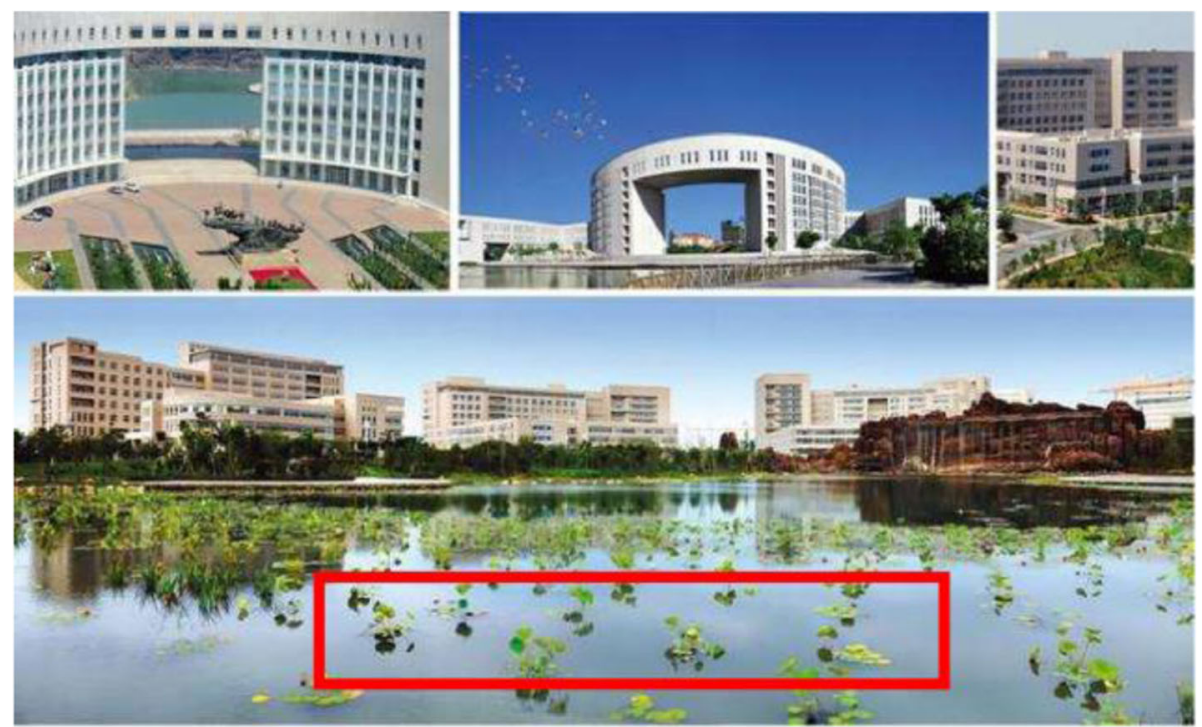

Fig. 26 Landscape Lake and green belts in eco-city' 


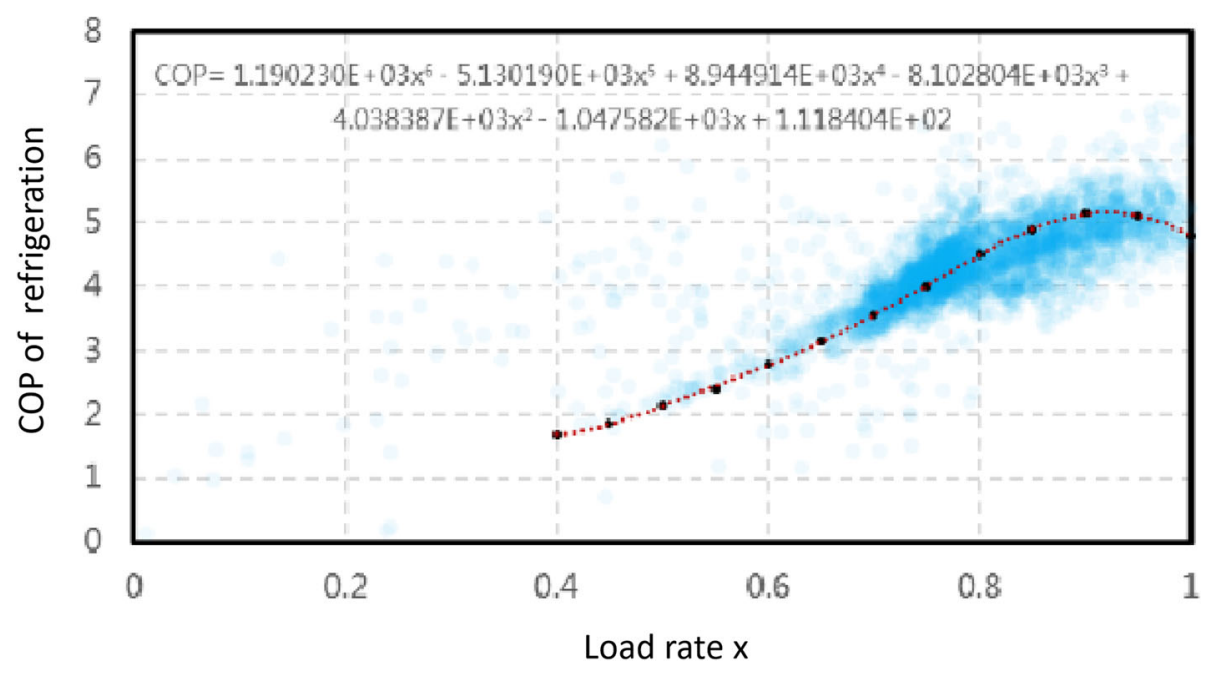

Fig. 27 Energy efficiency model of GSHP unit COP variation with load rate

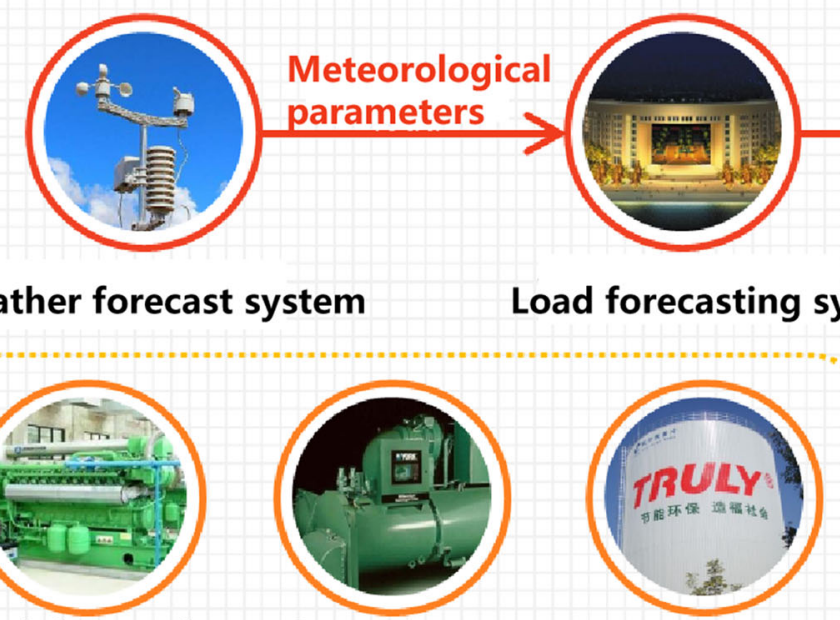

Triple supply Ground source Energy storage system

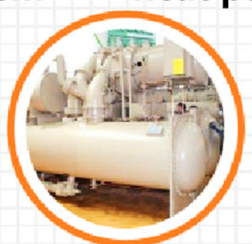

Electric refrigeration system

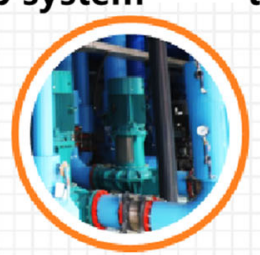

Transport system tank

\section{Energy system efficiency model}

Fig. 28 Optimal operation scheduling platform of energy station 
As a demonstration project of eco-city multi energy comprehensive use, the project adopts GSHP, cold storage and heat storage, combined cooling, heating, and power supply and other energy technologies [21], as shown in Table 2.

The project has 1831 double U-shaped buried pipes with a depth of $120 \mathrm{~m}$, all of which are located under the Landscape Lake and green belts in the park (Fig. 26). Ground temperature observation holes are also set up in the buried pipe area to analyze changes in the ground temperature during long-term operation.

The project is equipped with a complete operational data monitoring system. In relation to GSHP, our research group has used the big data method to establish an energy efficiency model of the GSHP unit by analyzing thousands of real operational data points over a span of 3 years. The calculated variations of COP with load rate are depicted in Fig. 27, and show a good match with the sample data of the manufacturers, indicating strong applicability of the model.

In addition, our project team has built an energy efficiency model of triple generation units, electric refrigeration units, and other equipment. The energy station optimization operation scheduling platform was then established as shown in Fig. 28. The platform can forecast the building cooling / heating load over the next $24 \mathrm{~h}$ according to weather forecast data and historical operational data, and comprehensively consider the time-of-the-time electricity price, equipment energy efficiency level, and other factors. When economic optimization is the goal, the platform provides the optimal scheduling strategy of the energy system through an optimization algorithm.

\section{Conclusion}

This paper summarizes the classification, development history and utilization status of shallow GSHPs, and analyzes their characteristic. Several typical engineering cases are described to present the development trends of shallow GSHPs. Main conclusions are summarized as follows:

(1) GSHPs have the characteristics of being economic and energy saving as well as offering environmental protection benefits. However, GSHPs can cause imbalance problems between energy extraction from and injection into the soil formations, and require large land area for well drilling and pipe burying.

(2) As an important renewable energy technology, GSHPs have been successfully applied in China. It is a main method of using renewable energy and will become a new growth point in China's urban economic development.

(3) New technologies to promote the energy-saving effect and environmental benefits of GSHP systems are analyzed. The hybrid system can be used to solve the imbalance of energy extraction from and injection into the soil, while the required large construction area can be decreased by optimizing the heat transfer performance of GSHPs, such as by increasing the heat exchange area and using phase change enhancement. Finally, GSHP systems coupled with other energy sources are an important way of promoting renewable energy.

Abbreviations

GSHP: Ground source heat pump; GCHP: Ground-coupled heat pump; TRT: Thermal response test; HDPE: High-density polyethylene; TRCM: Thermal resistance and heat capacity network method; CFD: Computational fluid dynamics; COP: Coefficient of performance

\section{Acknowledgements}

Not applicable.

\section{Authors' contributions}

Chaofan Song contributed the classification, development history, and utilization status of shallow ground source heat pumps, the promising development trends and some advanced technologies; Yang Li contributed the case analysis; Taha Rajeh and Ling Ma contributed the theoretical framework; Jun Zhao and Wenjia Li reviewed and edited the manuscript. All authors improved the manuscript. The author(s) read and approved the final manuscript.

\section{Funding}

This research is supported by "Key scientific issues in transformative technologies: intelligent evolution mechanism and design of distributed information energy system (2018YFA0702200)".

\section{Availability of data and materials}

The processed data required to reproduce these findings cannot be shared at this time as the data also forms part of an ongoing study.

\section{Declarations}

Ethics approval and consent to participate Not applicable.

\section{Consent for publication}

Not applicable.

\section{Competing interests}

We declare that we have no financial and personal relationships with other people or organizations that can inappropriately influence our work. There is no professional or other personal interest of any nature or kind in any product, service and/or company that could be construed as influencing the manuscript entitled, "Application and Development of Ground Source Heat Pump Technology in China".

Received: 29 October 2020 Accepted: 22 April 2021

Published online: 24 May 2021

References

1. Zhou, L., Zhang, D., Wu, W., Zhu, M., Yang, H., Li, C., Cui, M. (2018). A comparative study on grid resource utilization rate between China Southern Power Grid and National Grid plc of UK. Protection and Control of Modern Power System, 3(1), 26. https://doi.org/10.1186/s41601-018-0100-6.

2. Yi Yuechun. Summary of China Renewable Energy Development Report 2019 [EB]/ [OL]. https://wenku.baidu.com/view/c5e4244d0b12a21614791711 cc7931b765ce7ba2.html?fr=search-1_income5. Accessed 25 July 2020.

3. Xu, W. (2019). China ground source heat pump development research report (2018) [M]. Beijing: China Construction Industry Press.

4. China geothermal energy development report (2018) [R]. Ministry of natural resources, China Geological Survey, Department of new and renewable energy, national energy administration, Chinese Academy of Sciences, 
Institute of resources and environmental policy, development research center of the State Council, 2018

5. Wang, W., Wang, G., Zhu, X., \& Zhiming, L. (2017). Conditions and potential evaluation of shallow geothermal energy development and utilization in provincial capital cities of China [J]. Geology of China, 44(06), 1062-1073.

6. Lin, W. (2012). Study on thermal storage capacity and utilization of shallow geological environment [D]. Chinese Academy of Geological Sciences.

7. Yuanpu, L., Gebert, L., \& Xiuguo, L. (2002). Promotion of ground source heat pump technology in China [J]. Energy Conservation and Environmental Protection, 12, 20-23.

8. $\mathrm{Yu}, \mathrm{L}$. (2004). Heat transfer performance and experimental study on U-tube heat exchanger of ground source heat pump [D]. Tianjin: Tianjin University.

9. Zhu, Q. (2008). Research on the application of renewable energy ground source heat pump air conditioning system in Tianjin [D]. Tianjin: Tianjin University.

10. Chunlei, Z. (2005). Study on performance and underground temperature field of U-tube ground source heat pump system [D]. Thermal engineering, Tianjin: Tianjin University.

11. Dongli, Y., Guo, Q., Xiaolin, C., \& Jinshan, J. (2004). Air conditioning design of Beijing Tianchuang Shiyuan project [J]. HVAC, 05, 77-79.

12. Wei, X., Jinqiu, L., Yang, B., Yu, J., \& Lin, B. (2019). Introduction to energy planning and terminal energy saving design of Daxing international airport []]. Building Energy Conservation, 47(10), 9-14.

13. Xu, Y. (2005). Ground source heat pump central air conditioning system of Beijing Tianhu international conference hotel [J].

14. Kuishan, L., Wu, L. H., Liang, T., Dafa, Y., Jun, L., \& Zhang, X. (2010) Application of ground source heat pump in expo Axis and underground complex [J]. HVAC, 40(08), 78-81.

15. Dongsheng, L., \& Youhong, S. (2003). Ground source heat pump technology, a new technology for shallow ground energy utilization [J]. Geotechnical Engineering Technology, 01, 57-59.

16. Zhao, J., Li, Y., \& Wang, J. (2016). A review on heat transfer enhancement of borehole heat exchanger [J]. Energy Procedia, 104, 413-418. https://doi.org/1 0.1016/j.egypro.2016.12.070

17. Aydın, M., \& Sisman, A. (2015). Experimental and computational investigation of multi U-tube boreholes. Applied Energy, 145, 163-171.

18. Zarrella, A., De Carli, M., \& Galgaro, A. (2013). Thermal performance of two types of energy foundation pile: Helical pipe and triple Utube. Appl Therm Eng, 61(2), 301-310. https://doi.org/10.1016/.applthermaleng.2013.08.011.

19. He, Y., Chen, Y., Yang, Z., He, H., \& Liu, L. (2018). A review on the influence of intelligent power consumption technologies on the utilization rate of distribution network equipment. Protection and Control of Modern Power System, 3(1), 18. https://doi.org/10.1186/s41601-018-0092-2.

20. Lu, H., Dong, Y., Jin, L., Wenwen, Z., \& Zhu, J. (2020). Study on optimal configuration of coupling system of multi energy utilization mode based on ground source heat pump [J]. Shanghai Energy Conservation, 01, 33-38.

21. Gao, Y. (2016). Research on joint dispatching strategy for economic operation of regional energy stations [D]. Tianjin: Tianjin University.

\section{Submit your manuscript to a SpringerOpen ${ }^{\circ}$ journal and benefit from:}

- Convenient online submission

Rigorous peer review

- Open access: articles freely available online

High visibility within the field

- Retaining the copyright to your article

Submit your next manuscript at $\boldsymbol{\nabla}$ springeropen.com 